\title{
Optimal control of ceramsite burning in a rotary kiln
}

\author{
Stanislav Galitskov ${ }^{1}$, Konstantin Galitskov ${ }^{1}$, Oleg Samokhvalov ${ }^{1, *}$, and Aleksandr Fadeev ${ }^{1}$ \\ ${ }^{1}$ Samara State Technical University, Institute of Architecture and Civil Engineering, \\ Molodogvardeyskaya str. 194, 443001 Samara, Russia
}

\begin{abstract}
The paper considers various methods and devices of optimal control of ceramsite burning in a rotary kiln. All this ensures ceramsite production with required values of its density or strength at minimum energy consumption under conditions of maximum achievable productivity.
\end{abstract}

\section{Introduction}

Ceramsite with different values of density or strength is used in different building spheres $[1,2]$. In this regard, ceramsite producing factories should provide a flexible regime of changing technologies and equipmentto provide quick change of type of ceramsite it produces.

Currently known algorithms and kiln control devices are known to have strict There are also difficulties in monitoring parameters of ceramsite temperature field. Papers [3-5] introduce a method of monitoring ceramsite temperature in three so-called kiln bearing cross-sections A, C, F. Papers [3, 6] show that this method makes possible to purposefully change the burning curve within comparatively wide limits by changing the following three control actions: extensive thermal power of the burner $-\mathrm{Q}_{\mathrm{b}}$, the kiln load factor $\mathrm{Q}_{1}$ and the kiln angular velocity $\omega$ (see Figure 1). This enables to expand technological capacity of the kiln in regard of density and strength of ceramsite produced. That is why it is important and actual to find optimal conditions of ceramsite burning in regard of its density $\rho$ or strength $\mathrm{R}$ in conditions of energy consumption reduction.

\section{Burning Ceramsite SAC Structure}

Mathematical models of ceramsite burning introduced in Papers [3, 7] made it possible to generate a structure of the model of burning process as a multi-dimensional object with distributed parameters which status is defined by the vector of output coordinates including temperature values in bearing sections $\bar{X}_{\text {выx }}=\left[\mathrm{T}_{\mathrm{F}}, \mathrm{T}_{\mathrm{A}}, \mathrm{T}_{\mathrm{C}}\right]^{\mathrm{T}}$. Vector $\overline{\mathrm{X}}_{\mathrm{Bx}}=\left[\mathrm{Q}_{\mathrm{r}}, \mathrm{Q}_{3}, \omega\right]^{\mathrm{T}}$ is taken as input influences. Besides, the following functional relationships are established:

$$
\rho=f_{2}\left(T_{A}, T_{C}, w, \gamma\right)
$$

* Corresponding author: indexcitir@gmail.com 


$$
R=f_{I}\left(T_{F}, T_{A}, T_{C}, w, \gamma\right)
$$

where $\mathrm{w}$ and $\gamma$ are raw material moisture and clay generalized characteristics that make possible to determine strength and density of ceramsite produced. In accordance with the object characteristics the authors generated the structure of a three-dimensional automatic control system (see Figure 2) and parametrically optimized egulators of its separate channels.

\section{Optimal Control Regimes}

While dealing with the problem of burning process optimization the researchers considered two tasks of great practical importance. The first task is connected with light ceramsite of $\rho_{\text {req }}$, required density, and the second deals with high-strength ceramsite production with required strength of $R_{\text {req. }}$.

An algorithm for handling the first task involves the following steps. Firstly, exploring the properties of raw material blowup with w humidity (obtained from clay with a known constant $\gamma$ value), it is possible to build Surface 1 in the space $\mathrm{OT}_{\mathrm{A}} \mathrm{T}_{\mathrm{C}} \rho$ with the expected density of ceramsite with variations of $\mathrm{T}_{\mathrm{A}}$ и $\mathrm{T}_{\mathrm{C}}[8,9]$ within the range limited by the top and bottom points of the burning curve (see Figure 3 ).

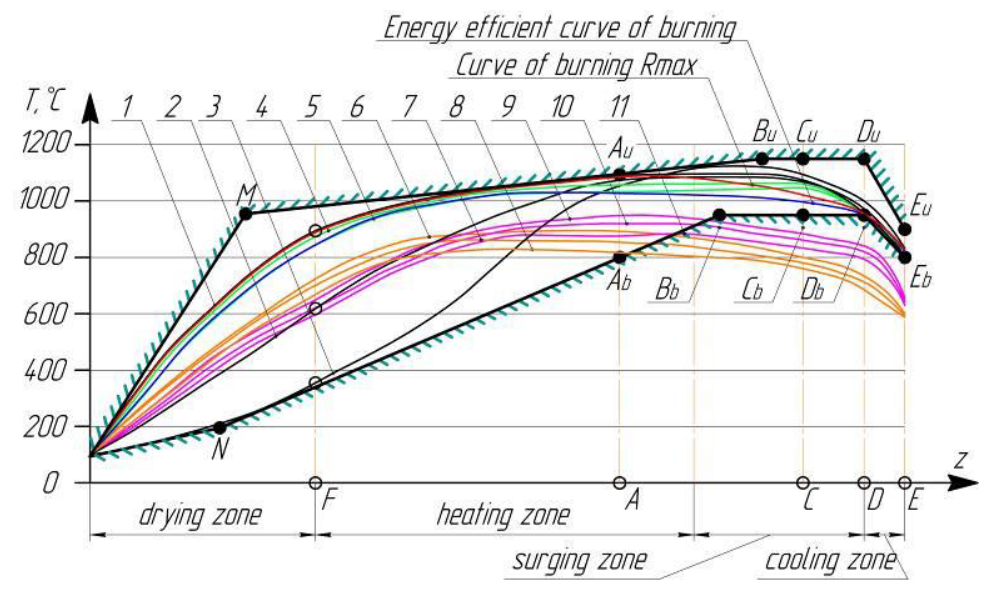

Fig.1. Burning curves area for high-strength ceramsite.

In the second phase, in accordance with the required value $\rho_{\text {req }}$ we determine optimal temperature $\mathrm{T}_{\mathrm{A}}{ }^{\text {opt }}$ and $\mathrm{T}_{\mathrm{C}}{ }^{\text {opt }}$ along Surface (1). Temperature value here lie on the required burning curve presented as $\mathrm{ABC}$ polygonal line. $\mathrm{T}_{\mathrm{A}}{ }^{\text {opt }}$ and $\mathrm{T}_{\mathrm{C}}{ }^{\text {opt }}$ values are predetermined for the two corresponding channels of the system (see Figure 2). The third channel operates in a mode of kiln rotation with nominal speed.

To produce ceramsite with required density value $R_{\text {req }}$ in conditions of energy consumption reduction, let us consider phase field $\mathrm{OT}_{\mathrm{C}} \mathrm{T}_{\mathrm{A}} \mathrm{T}_{\mathrm{F}}$. In this field we'll use a methodology introduced in Paper [5] on the basis of Dependence (2) and get thermal-stress characteristics of burning ceramsite of requited density in conditions of energy consumption reduction and with maximal possible productivity (see Figure 4):

$$
R=f_{3}\left(T_{F}^{o p t}, T_{A}^{o p t}, T_{C}^{o p t}, w, \gamma\right) .
$$


When we find $\mathrm{R}_{\text {req }}$ point on this curve, we get the required values $\mathrm{T}_{\mathrm{C} . \mathrm{p} p}^{\text {opt }}, \mathrm{T}_{\mathrm{A} . \mathrm{pp}}^{\text {opt }}$ and $\mathrm{T}_{\mathrm{F} \text {.pp }}^{\text {opt }}$, supported by the automatic control system (see Figure 2).

\section{Optimal Control Efficiency}

To assess the effectiveness of the proposed method of choosing optimum regimes of coordinated control of the kiln work while producing ceramsite with required density of $\rho_{\text {req }}$ the authors performed a comparative analysis of gas expense for ceramsite blowup $1 \mathrm{~m}^{3}$ on conditions of realization of the proposed algorithm (Curve 2, Figure 5). The authors also used a heuristic algorithm, in which the management of blowup is performed by changing power $\mathrm{Q}_{\mathrm{p}}$ of the burner with the same loading of the kiln and the same speed of its rotation (Curve 1, Figure 5). This simulation study [10] is done for the regime, when the constant loading was $\mathrm{Q}_{\mathrm{z}}=4.5 \mathrm{t} / \mathrm{h}$ and humidity of material $\mathrm{w}=15 \%$. This research was carired out for six values Qח $=28000 ; 30000 ; 32000 ; 34000 ; 36000 ; 38000 \mathrm{~W} / \mathrm{m}^{3}$. Gas expense for ceramsite blowup $1 \mathrm{~m}^{3}$ is determined by $\sigma_{0 \Gamma}=Q_{T} / P$, where $Q_{T}-$ is fuel consumption; $P$ kiln productivity, $\mathrm{P}=\left(\mathrm{q}_{3} \mathrm{~K}_{\mathrm{bl}}\right) / \rho_{\mathrm{c}}$.

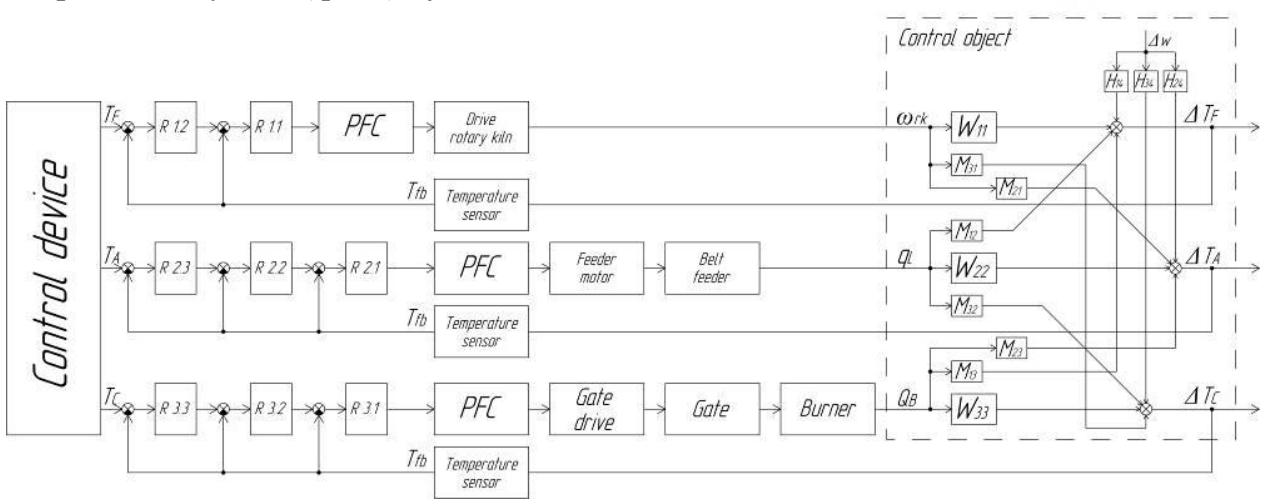

Fig. 2. The structure of a multidimensional system of automatic stabilization of ceramsite strength.

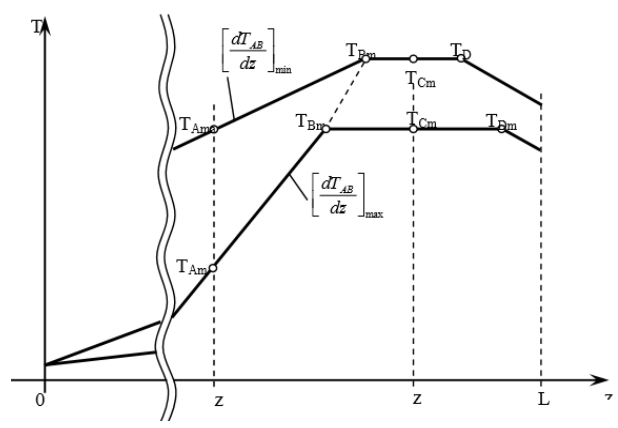

Fig. 3. Boundary curves of ceramsite burning. 


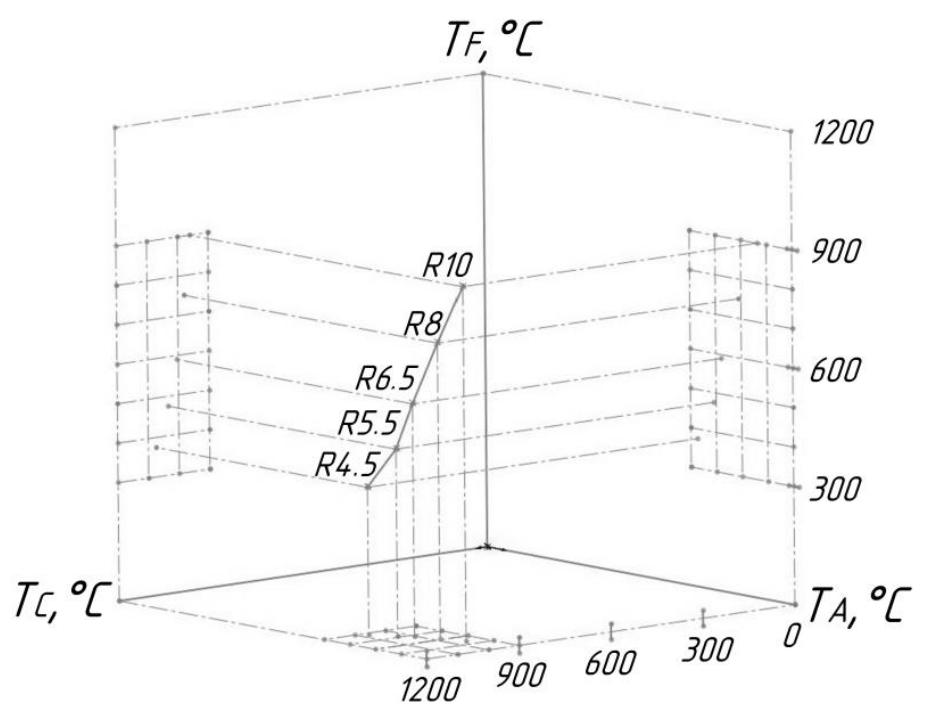

Fig. 4. Temperature and mechanical strength characteristics for ceramsite burning.

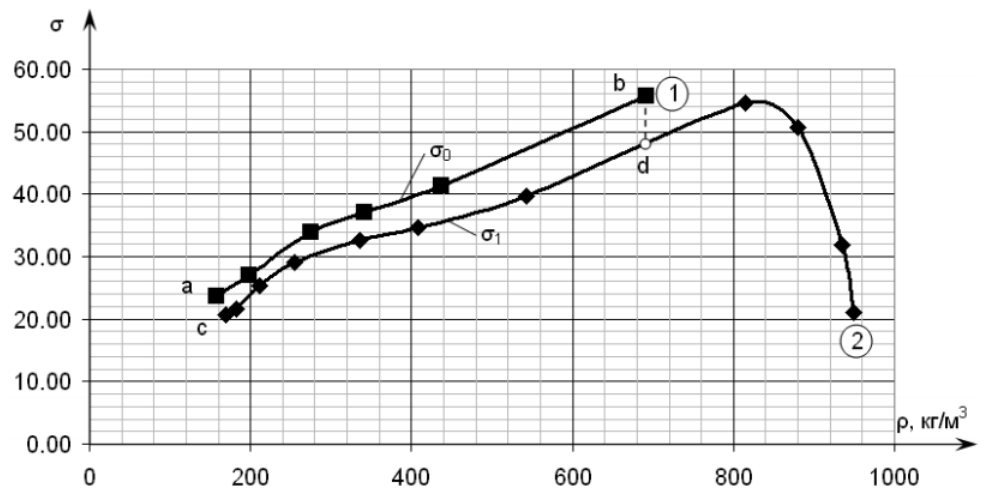

Fig. 5. Energy consumption for ceramsite production in density function.

Figure 5 compares Curves 1 and 2. This comparison shows that for a kiln of $2.5 \times 40 \mathrm{~m}$ type while using clay from Smyshlyaevka the system of coordinated control allows to reduce energy consumption for ceramsite burning by $11-15 \%$.

Assessment of this methodology efficiency was carried out on the same basis for selecting optimal regimes for coordinated control of the kiln while producing ceramsite with required strength of $\mathrm{R}_{\text {тр }}$. Figure 6 presents simulation study results. Here Curve 3 corresponds to the use of optimal control regime of the kiln while producing ceramsite with required strength of $\mathrm{R}_{\text {req }}$ by a three-channel $\mathrm{SAC}$. 


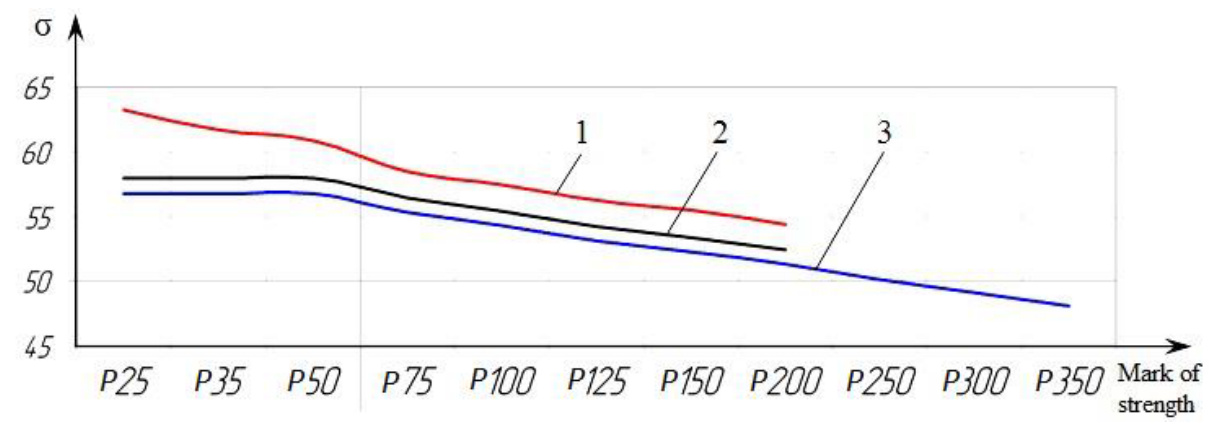

Fig. 6. Energy consumption for ceramsite production in strength function.

\section{Conclusions}

1. The paper establishes the criterion for optimal control of the burning process: production of ceramsite of required strength $R_{\text {req }}$ or required density $\rho_{\text {req }}$ on conditions of maximum possible productivity and minimum energy consumption.

2. The paper demonstrates that one of the possible solutions of the task is the coordinated control of three coherent control actions: extensive thermal power of the burner $-\mathrm{Q}_{\mathrm{b}}$, the kiln load factor $\mathrm{Q}_{1}$ and the kiln angular velocity $\omega$. The authors also generated the structure of a multi-dimensional automatic control system of the kiln.

3. The paper introduces a new methodology of calculating optimal temperature in three bearing sections in regard to production of light ceramsite of $\rho_{\text {req }}$ required density, and of high-strength ceramsite with required strength of $R_{\text {req }}$.

The paper proves that coordinated control extends technological properties of the kiln and helps reduce energy consumption for ceramsite burning by $11-15 \%$ while producing ceramsite with required strength of $R_{\text {req }}$ or with required density of $\rho_{\text {req. }}$.

\section{References}

1. V.M. Gorin, T.A. Tokareva, M.K. Kabanova, Building materials 1, 9-11 (2010)

2. Yu.S. Vytchikov, M.Ye. Saparev, Construction materials 11, 12-15 (2013)

3. S.Ja. Galitskov, K.S. Galitskov, O.V. Samohvalov, A.S. FadeevScience Review 7, $227-$ 237(2015)

4. S.Ja. Galitskov, O.V. Samokhvalov, A.S. Fadeev, Patent 2554964. Method for burning expanded clay in rotary kiln and device for its implementation, BI, 19 (2015)

5. K.S. Galitskov, O.V. Samohvalov, Industrial and Civil Engineering 9, 91-94 (2015)

6. S.P. Onatskiy, Ceramsite production, 3-d ed. (Stroyizdat, Moscow, 1987)

7. A.S. Fadeev, S.Ya. Galickov, A.I. Danilushkin, Vestnik of Samara State Technical University. Technical Sciences Series 2(30), 160-168 (2011)

8. S.Ya. Galitskov, A.S. Fadeev, Collected works of 69th all-Russia scientific technical conference, Samara State University of Architecture and Civil Engineering, 514-515 (2012)

9. S.Ya. Galitskov, A.S. Fadeev, O.V. Samohvalov, Procedia Engineering, 111, 233-235 (2015)

10. S.Ya. Galitskov, A.S. Fadeev, Vestnik SGASU, Town Planning and Architecture 4 (12), 95-98 (2013) 